\title{
Study of Parasitic Trapping in Alumina used as Blocking Oxide For Non Volatile Memories
}

\author{
J. P. Colonna ${ }^{1}$, M. Bocquet ${ }^{1}$, G. Molas ${ }^{1}$, N. Rochat ${ }^{1}$, P. Blaise ${ }^{1}$, H. Grampeix ${ }^{1}$, C. \\ Licitra $^{1}$, D. Lafond ${ }^{1}$, L. Masoero ${ }^{1}$, V. Vidal ${ }^{1}$, J. P. Barnes ${ }^{1}$, M Veillerot $^{1}$ and K Yckache ${ }^{1}$ \\ 1 -CEA-LETI, Minatec, 17, Av des Martyrs, 38054 GRENOBLE Cedex 9, France \\ corresponding author e-mail: jean-philippe.colonna@cea.fr
}

\begin{abstract}
Alumina layers deposited by Atomic Layer Deposition followed by Rapid Thermal anneal were characterized. We found that the crystallization of alumina in $\gamma$-phase occurs between 700 and $850^{\circ} \mathrm{C}$. Optical band gap, stress and density were found to increase upon crystallization Hydrogen content in alumina was characterized by ToF-SIMS and infrared spectroscopy. We found that annealing ambience has a strong influence on hydrogen concentration: oxygen favors hydrogen desorption from alumina. Finally, charge trapping in alumina was characterized by $\mathrm{C}(\mathrm{V})$ measurements. A strong correlation between hydrogen concentration and trapping was established.
\end{abstract}

\section{Introduction}

TANOS memories $\left(\mathrm{TaN}-\mathrm{Al}_{2} \mathrm{O} 3-\mathrm{Si}_{3} \mathrm{~N}_{4}-\mathrm{SiO}_{2}-\mathrm{Si}\right)$ are among the best candidates for sub32nm generation of Non Volatile Memory. The nitride charge trapping layer ensures a good resistance to the SILC (Stress Induced Leakage Current) effect, the alumina blocking oxide improves the coupling ratio and the metal gate reduces the erase saturation. However, retention and endurance are still major drawbacks of these structures. Some authors [1] link them with parasitic trapping in alumina. Alumina has been studied extensively recently, both its physical and electrical aspects, but the impact of the material properties on the parasitic 
trapping is not thoroughly understood. The present study will focus on the material properties of alumina, trying to correlate them with parasitic trapping.

\section{Experimental and Physical Characterization}

$15 \mathrm{~nm}$ of alumina were deposited by Atomic Layer Chemical Vapor Deposition (ALCVD) at $350^{\circ} \mathrm{C}$ using trimethylaluminum (TMA) and $\mathrm{H}_{2} \mathrm{O}$ precursors. Rapid Thermal Anneals (RTA) were performed, from $700^{\circ} \mathrm{C}$ to $1050^{\circ} \mathrm{C}$ under $\mathrm{N}_{2}$ or $\mathrm{O}_{2}$. Physical characterization was performed on the different samples: stress measurements were done by the curvature method using the Stoney formula, thickness and density measurements were done by X-ray reflectometry (XRR) along with Infrared Spectroscopy in attenuated total reflection mode (ATR-FTIR). Stress, thickness and density measurements are summarized in Table I. Infrared spectroscopy results are presented in Figure 1.

\begin{tabular}{|c|c|c|c|c|c|c|c|}
\hline Anneal & As dep & $700^{\circ} \mathrm{C} \mathrm{N}_{2}$ & $850^{\circ} \mathrm{C} \mathrm{N} \mathrm{N}_{2}$ & $950^{\circ} \mathrm{C} \mathrm{N} \mathrm{N}_{2}$ & $1050^{\circ} \mathrm{C} \mathrm{N} \mathrm{N}_{2}$ & $700^{\circ} \mathrm{C} \mathrm{O}_{2}$ & $1050^{\circ} \mathrm{C} \mathrm{O}_{2}$ \\
\hline $\begin{array}{c}\text { Stress } \\
\text { (Mpa } \\
\text { tensile) }\end{array}$ & 300 & 300 & 1980 & 1700 & 1540 & 1880 & 1400 \\
\hline $\begin{array}{c}\text { XRR } \\
\text { Thickness } \\
\text { (A) }\end{array}$ & 150 & 142 & 122 & 122 & 125 & 150 & 124 \\
\hline $\begin{array}{c}\text { XRR } \\
\text { density } \\
\text { (g/cm3) }\end{array}$ & 3 & 3 & 3,5 & 3,5 & 3,5 & 3 & 3,5 \\
\hline
\end{tabular}

TABLE I: Thickness, Density and Stress

Two populations can be distinguished from these measurements: a low thermal budget population with as deposited and $700^{\circ} \mathrm{C}$ annealed samples, and a high thermal budget population (samples annealed at 850,950 and $1050^{\circ} \mathrm{C}-$ in italic). The low thermal budget population has stress values below a few hundred of MPa, a thickness of $15 \mathrm{~nm}$ and a density of $3 \mathrm{~g} / \mathrm{cm}^{3}$. The high thermal budget population has stress values between 1400 and 2000 
$\mathrm{MPa}$, a thickness of $12-12.5 \mathrm{~nm}$ - indicating a shrink- and a density of $3.5 \mathrm{~g} / \mathrm{cm}^{3}$. It is noticeable that the sample annealed at $700^{\circ} \mathrm{C}$ under $\mathrm{O}_{2}$ ambiance shows a thickness and a density coherent with the low thermal budget population, but a high value of stress.

As shown in Figure 1, the main peak located at $900-950 \mathrm{~cm}^{-1}$ corresponds to the LO mode (longitudinal optic) of the $\mathrm{Al}-\mathrm{O}$ bond. The second peak located around $1250 \mathrm{~cm}^{-1}$ corresponds to the $\mathrm{Si}-\mathrm{O}$ bond ( $\mathrm{LO}$ mode). A significant interfacial oxide regrowth can be noticed after the oxygen anneal at $1050^{\circ} \mathrm{C}$. Concerning the main $\mathrm{Al}-\mathrm{O}$ peak, two population can be distinguished based on the peak position and the Full Width Half Maximum (FWHM). These two populations (a large ATR peak at $925 \mathrm{~cm}^{-1}$ and a narrower ATR peak at $900 \mathrm{~cm}^{-1}$ ) correspond to the same high and low thermal budget populations distinguished from Table I. The FWHM corresponds to the order of the $\mathrm{Al}-\mathrm{O}$ bonds in the alumina layer, so the high thermal budget population with a narrower peak is more ordered than the low thermal budget population suggesting an amorphous and a crystalline population. One can be more precise: according to [2] the $\gamma$-phase can be identified from the shoulder at $780 \mathrm{~cm}^{-1}$.

FTIR-ATR: AI2O3 15nm

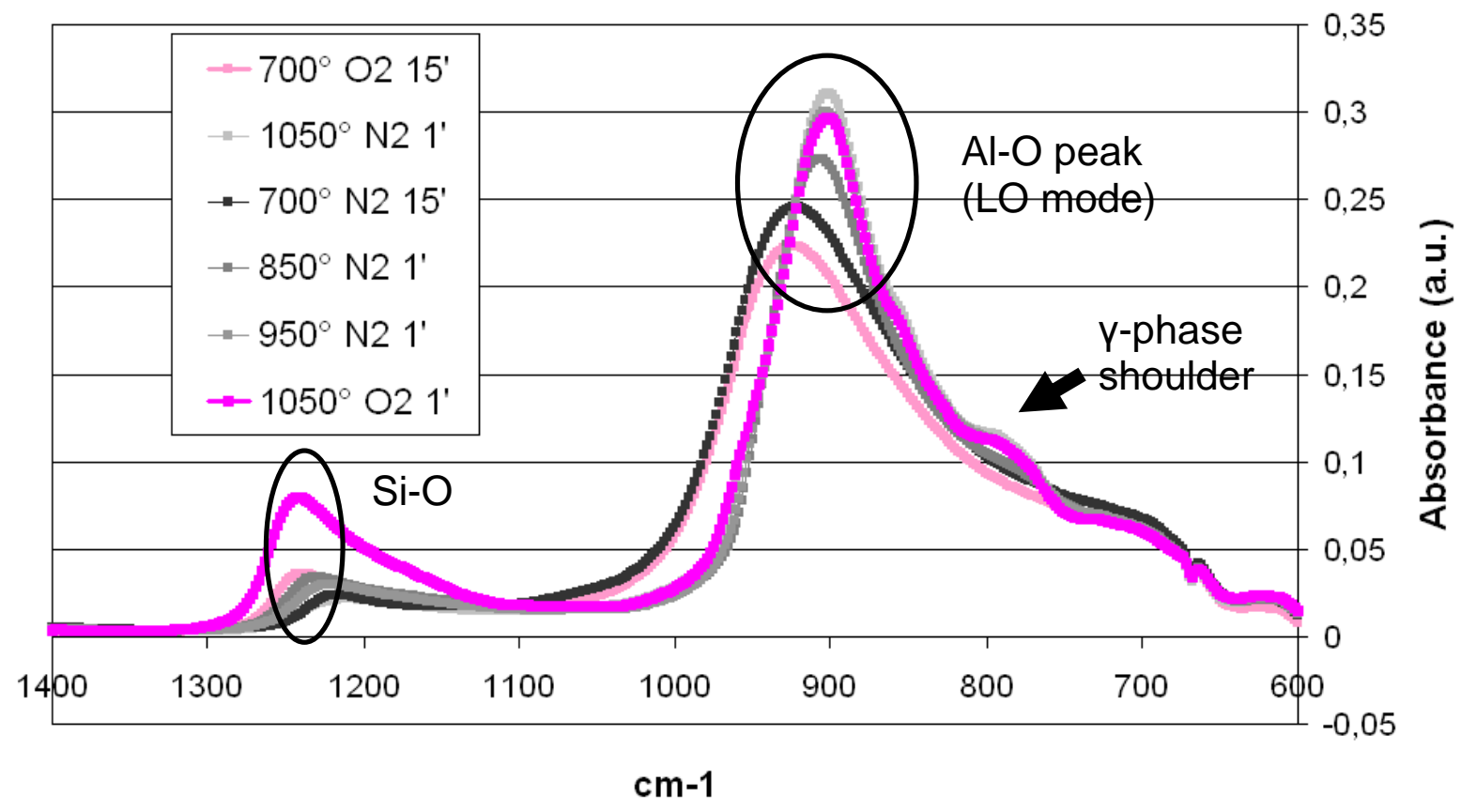


Fig. 1. FTIR-ATR Spectra of alumina with different annealing conditions

High resolution transmission scanning microscopy (HRTEM) pictures confirm the FTIRATR results. Figure 2 shows HRTEM pictures of the memory stack of $\mathrm{SiO}_{2} / \mathrm{Si}_{3} \mathrm{~N}_{4} / \mathrm{Al}_{2} \mathrm{O}_{3}$ annealed at 700 and $1050^{\circ} \mathrm{C}$. One can notice the crystalline structure of the $1050^{\circ} \mathrm{C}$ annealed alumina and its subsequent thickness shrink noticed in Table I (see red arrow in Fig 2.). This result confirms that the low thermal budget annealed samples correspond to amorphous state and the high thermal budget samples correspond to crystalline state.

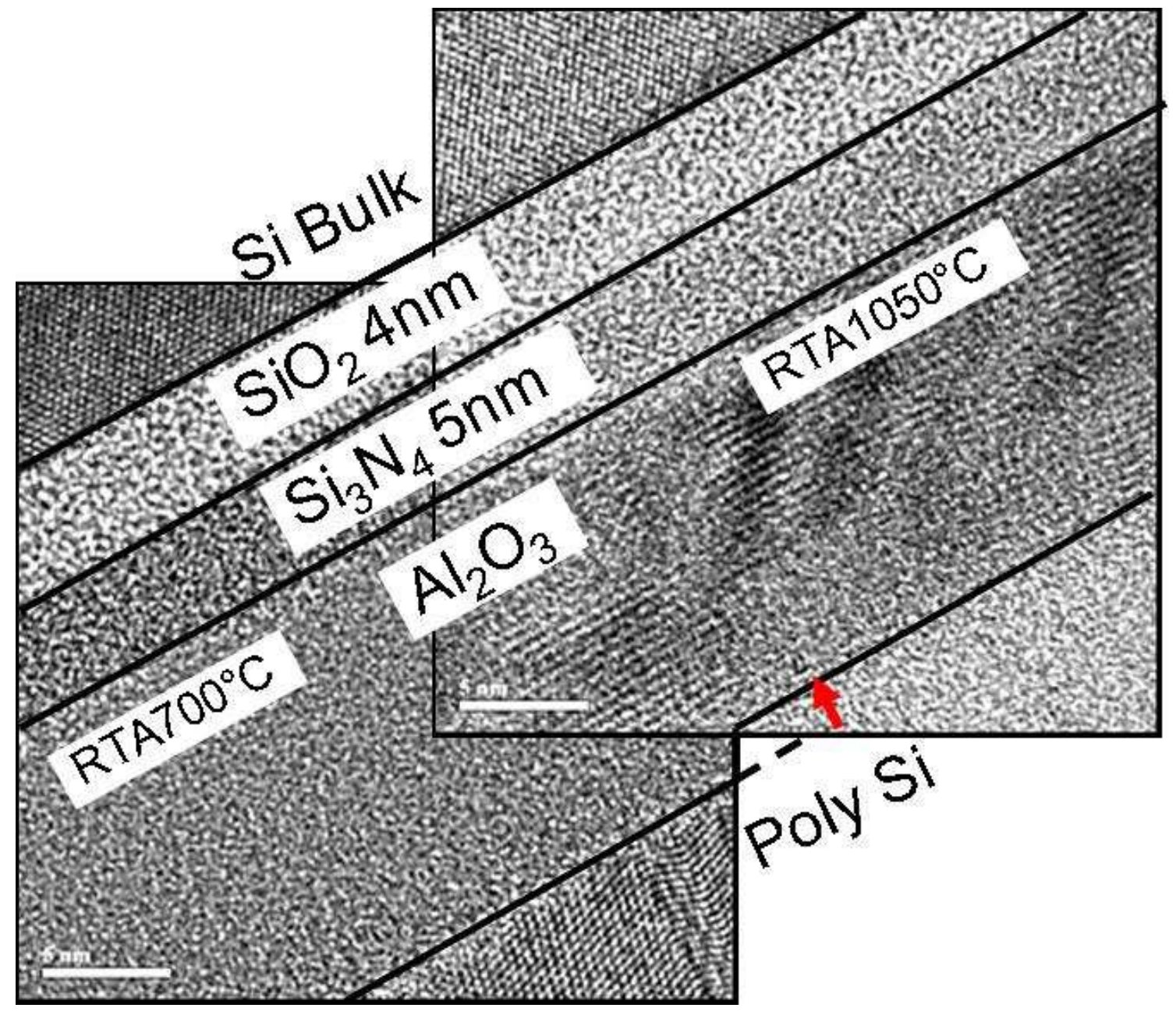

Fig. 2. HRTEM of $\mathrm{SiO}_{2} / \mathrm{Si}_{3} \mathrm{~N}_{4} / \mathrm{Al}_{2} \mathrm{O}_{3}$ annealed at 700 and $1050^{\circ} \mathrm{C}$ 


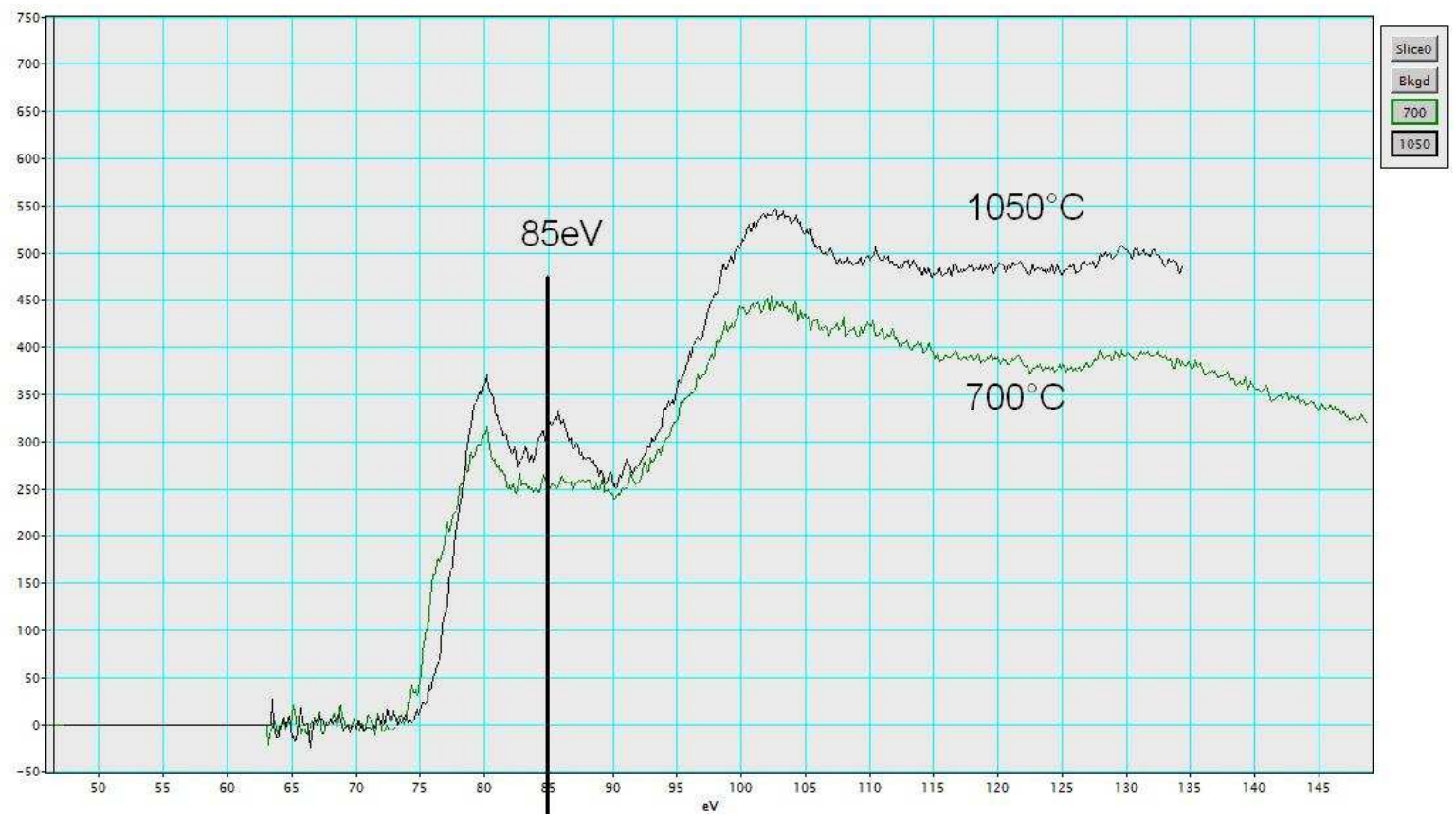

Fig. 3. EELS of $\mathrm{Al}_{2} \mathrm{O}_{3}$ annealed at 700 and $1050^{\circ} \mathrm{C}$

Electron energy-loss spectroscopy (EELS) was also performed on these two samples as shown in Figure 3. The peak at $85 \mathrm{eV}$ on the $1050^{\circ} \mathrm{C}$ annealed sample is typical of the $\gamma$-phase according to [3], which confirms the FTIR-ATR results. The $\gamma$-phase is usually described as a defective spinel, with two possible aluminium coordination: octahedral or tetrahedral [3][6].

Vacuum Ultraviolet Spectroscopic Ellipsometry (VUV-SE) was used to determine the optical properties of alumina samples. Refractive index $\mathrm{n}$ and extinction coefficient $\mathrm{k}$ are plotted for both 700 and $1050^{\circ} \mathrm{C}$ annealed samples as shown in Figure 4. Refractive index are similar for both crystalline and amorphous sample: $\mathrm{n}(1.5 \mathrm{eV})=1.73$ for crystalline alumina and 1.68 for amorphous alumina. The extinction coefficient $\mathrm{k}$ is rather different for the two samples. The energy band gap was extracted from the extinction coefficient measurement as explained in [4]. The amorphous sample show an energy band gap of $6.5 \mathrm{eV}$ while the crystalline sample has a band gap value of $7 \mathrm{eV}$. 


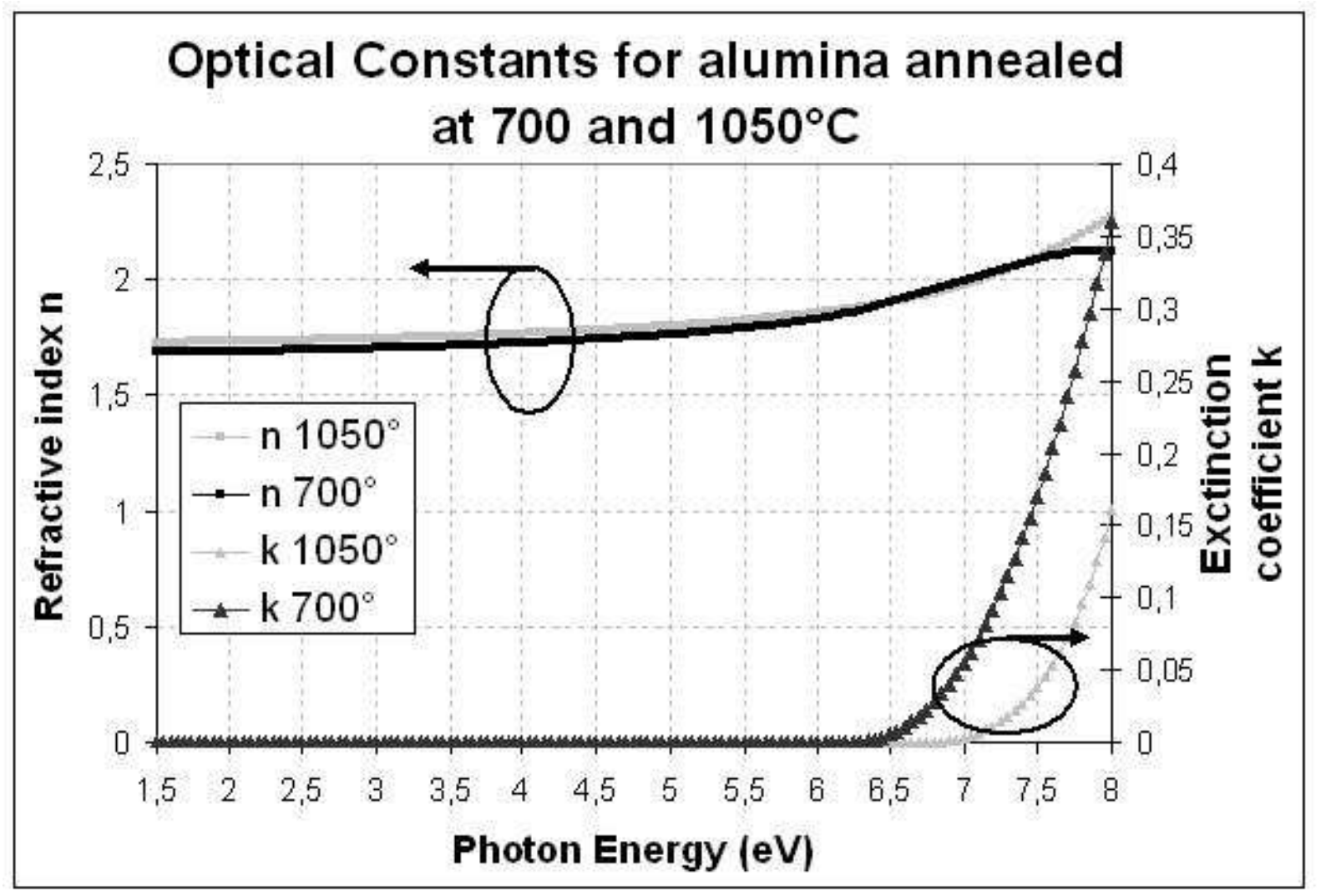

Fig. 4. Optical constant $\mathrm{n}$ and $\mathrm{k}$ of $\mathrm{Al}_{2} \mathrm{O}_{3}$ annealed at 700 and $1050^{\circ} \mathrm{C}$

\section{Hydrogen Characterization}

The hydrogen content of the different annealed alumina layers was then characterized using two techniques: infrared MIR (Multiple Internal Reflection) Spectrometry and ToFSIMS (TimeofFlight Secondary Ion Mass Spectroscopy). ToF-SIMS depth profiling (IONTOF V) has been performed using the following conditions:

- analysis gun: $25 \mathrm{keV} 4 \mathrm{pA} \mathrm{Bi1}+$; raster size $60 \mu \mathrm{m}$

- sputter gun: $1 \mathrm{keV} 13 \mathrm{nA} \mathrm{Cs+;} \mathrm{raster} \mathrm{size} 200 \mu \mathrm{m}$

- spectrometer: detection of negative ions

- $50 \mu$ s cycle time / interlaced mode

Fig 5 shows the ToF-SIMS hydrogen profile of alumina, as deposited, or after $\mathrm{O}_{2}$ or $\mathrm{N}_{2}$ annealing at different temperatures. The surface shows the highest hydrogen content for all samples. The bottom interface also shows high hydrogen content, with some differences upon 
annealing. The oxygen annealed samples have a larger interface (as seen in FTIR-ATR), with low hydrogen content for $1050^{\circ} \mathrm{C}$ oxygen annealed sample. One should also notice that sputter time might not be proportional to the sample thickness as etch rate might be different for amorphous and crystalline samples. The following remarks now concern the bulk of alumina. The highest hydrogen content is for the as deposited sample. For $\mathrm{N}_{2}$ annealed samples, hydrogen clearly decreases with increasing temperature. For $\mathrm{O}_{2}$ annealed samples, hydrogen content is low at both temperatures.

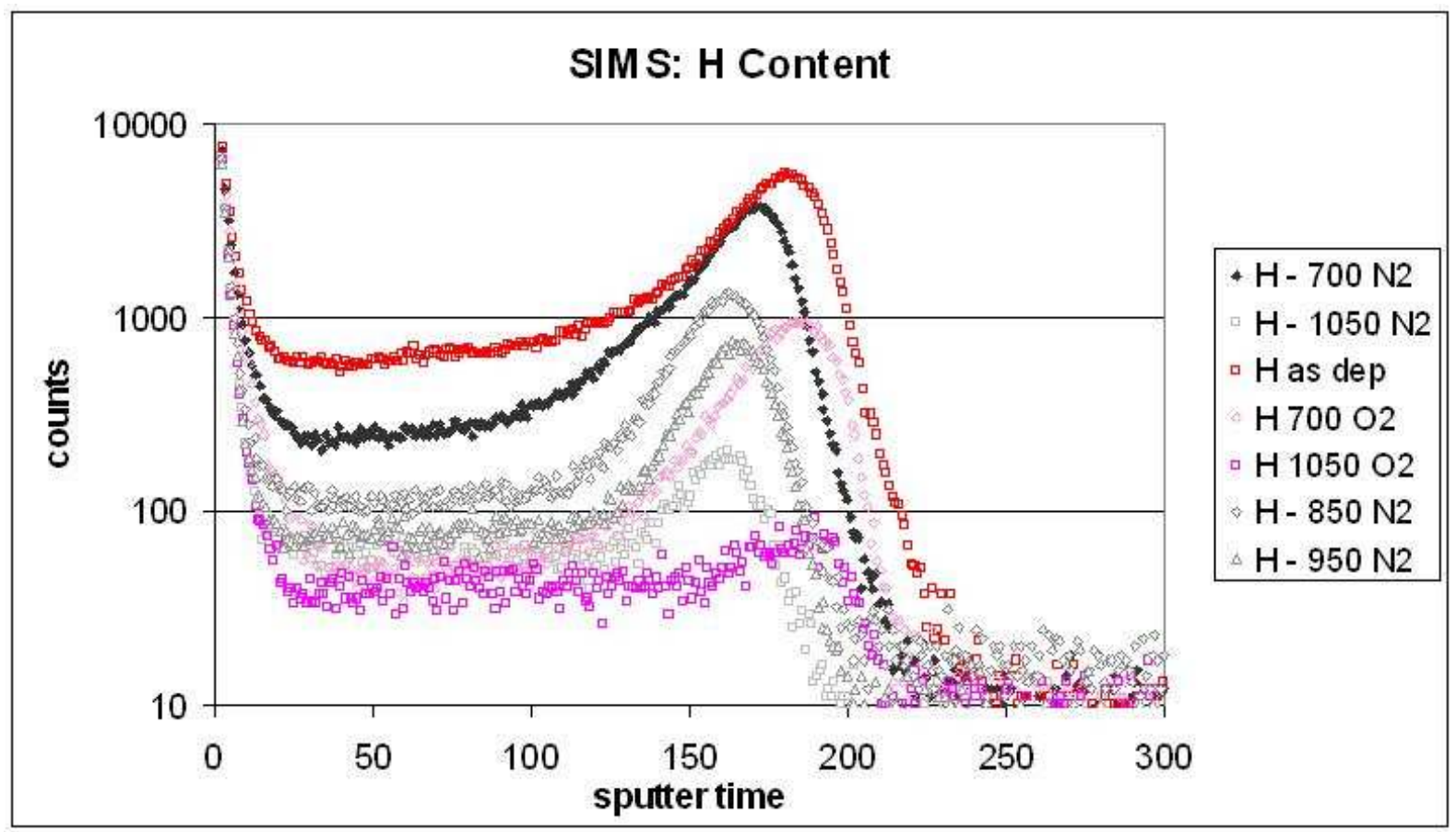

Fig 5. Tof-SIMS Hydrogen profile of $\mathrm{Al}_{2} \mathrm{O}_{3}$ after different anneal

Infrared MIR Spectroscopy [5] was then used for a qualitative analysis of hydroxyls groups $-\mathrm{OH}$ in amorphous and crystalline alumina, as shown in Figure 6. 


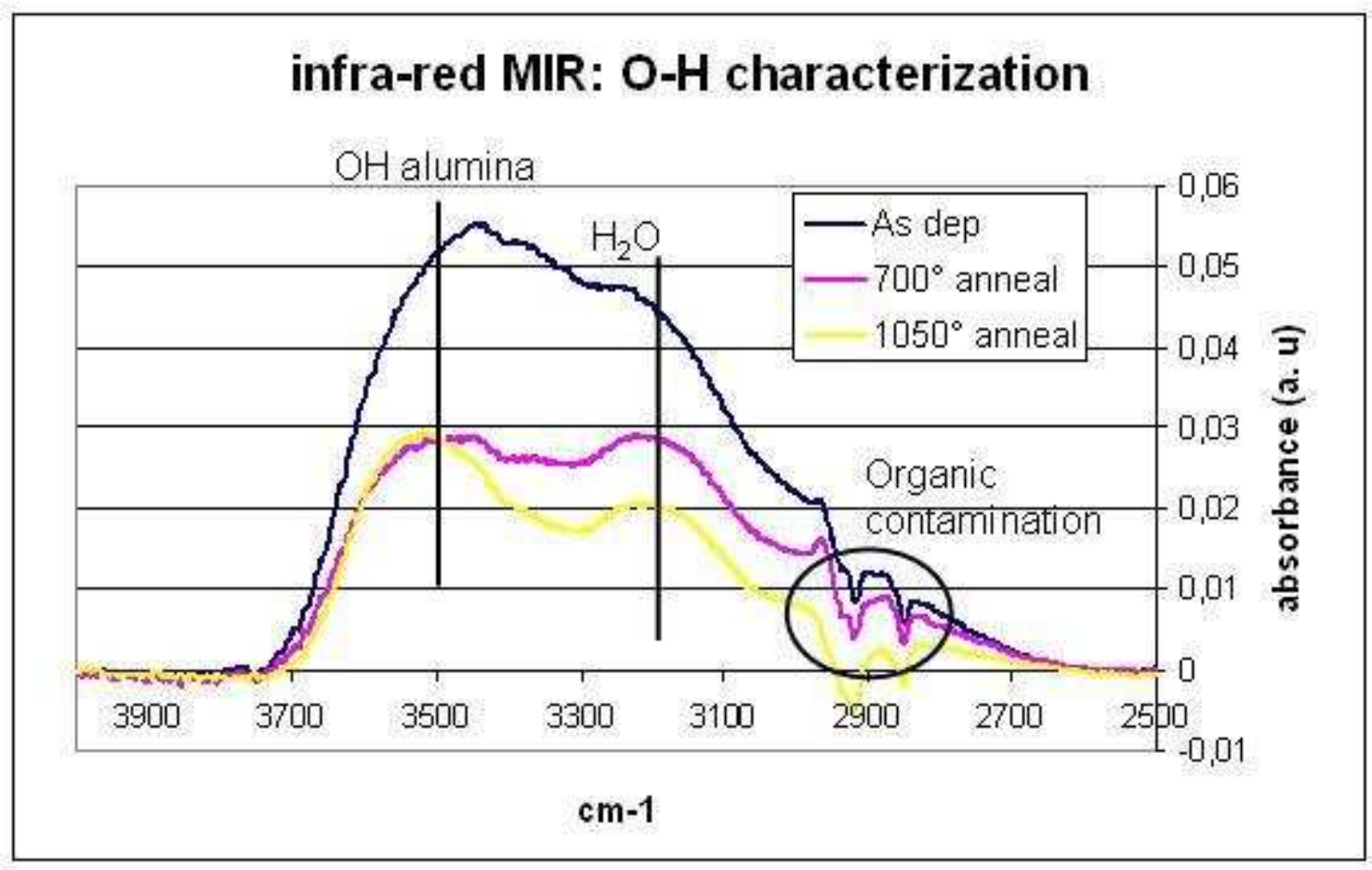

Fig 6. Infrared MIR spectra for amorphous and crystalline alumina

The main peak located at $3500 \mathrm{~cm}^{-1}$ corresponds to the $\mathrm{OH}$ stretching vibration in alumina according to [6]. A second peak centered at $3200 \mathrm{~cm}^{-1}$ corresponds to free $\mathrm{H}_{2} \mathrm{O}$ [5]. This second peak can be seen as surface hydration and therefore suggests that the surface contribution is important or even dominant in the measurement presented in Figure 6. In order to measure hydroxyls groups from the bulk of alumina, we did subtract the $\mathrm{OH}$ signal of a $8 \mathrm{~nm}$ thick alumina sample from a $15 \mathrm{~nm}$ thick sample. This subtraction therefore allows us to overcome the $\mathrm{OH}$ signal from both the surface and bottom interface. The results from this normalization are plotted in Figure 7 for alumina samples annealed at 700 and $1050^{\circ} \mathrm{C}$. 


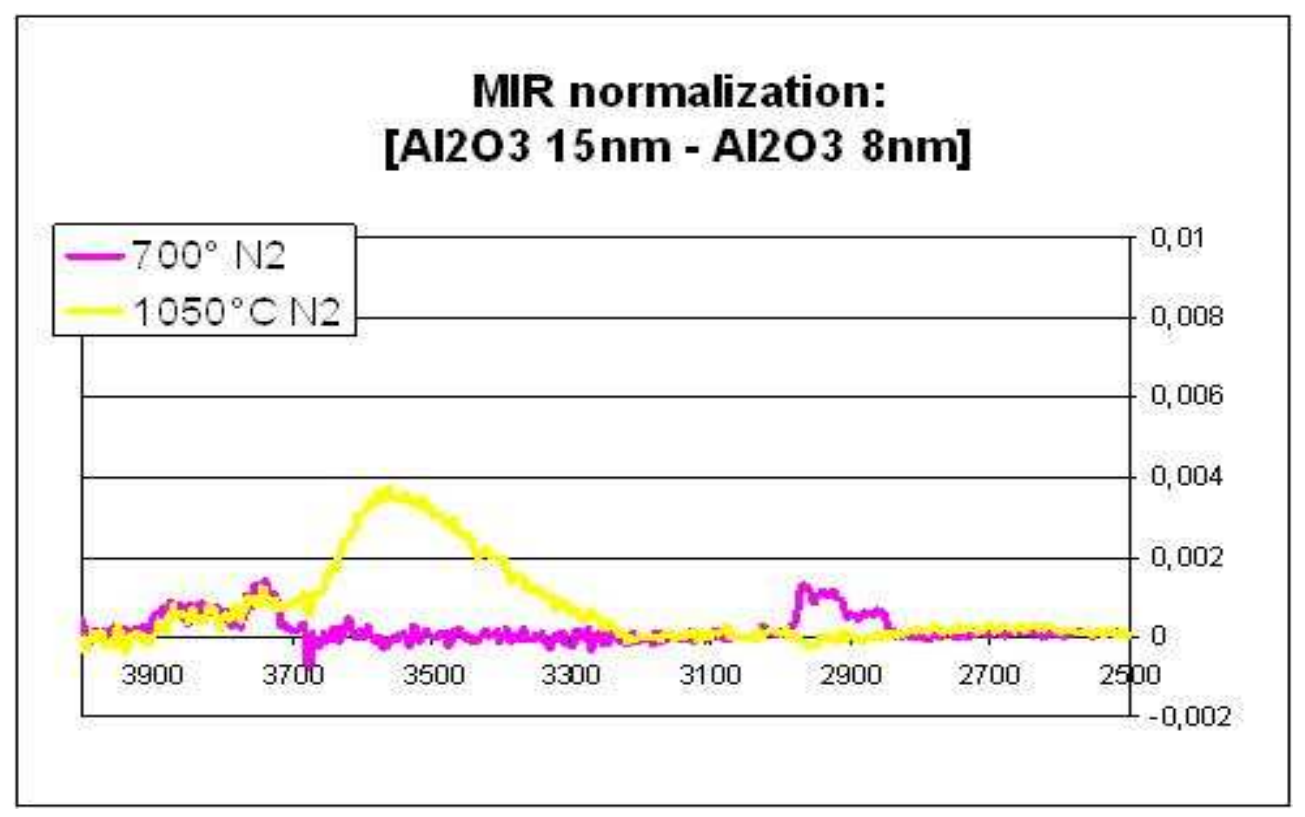

Fig. 7. Normalized MIR spectra of $\mathrm{Al}_{2} \mathrm{O}_{3}$ annealed at 700 and $1050^{\circ} \mathrm{C}$

The normalization shows that there is almost no $\mathrm{OH}$ in the bulk of an amorphous alumina annealed at $700^{\circ} \mathrm{C}$. This means that all the hydroxyls groups detected in Figure 6 come either from the surface or the interface. Concerning the crystalline sample annealed at $1050^{\circ} \mathrm{C}$, the normalization shows that a rather small signal from $\mathrm{OH}$ bulk is detected ( 7.5 times smaller than the signal from surface and interface from Fig 6.). In order to support this normalized MIR results, we plot the $\mathrm{OH}: \mathrm{H}$ ratio from Tof-SIMS measurements for samples as deposited and annealed at $700,850,950$ and $1050^{\circ} \mathrm{C}$ under nitrogen in Figure 8. Both $\mathrm{H}$ and $\mathrm{OH}$ signals from Tof-SIMS measurement decrease with increasing temperature, but the $\mathrm{OH}: \mathrm{H}$ ratio does increase with increasing temperature suggesting that $\mathrm{OH}$ are favored at high temperature and therefore supports the normalized MIR results. 


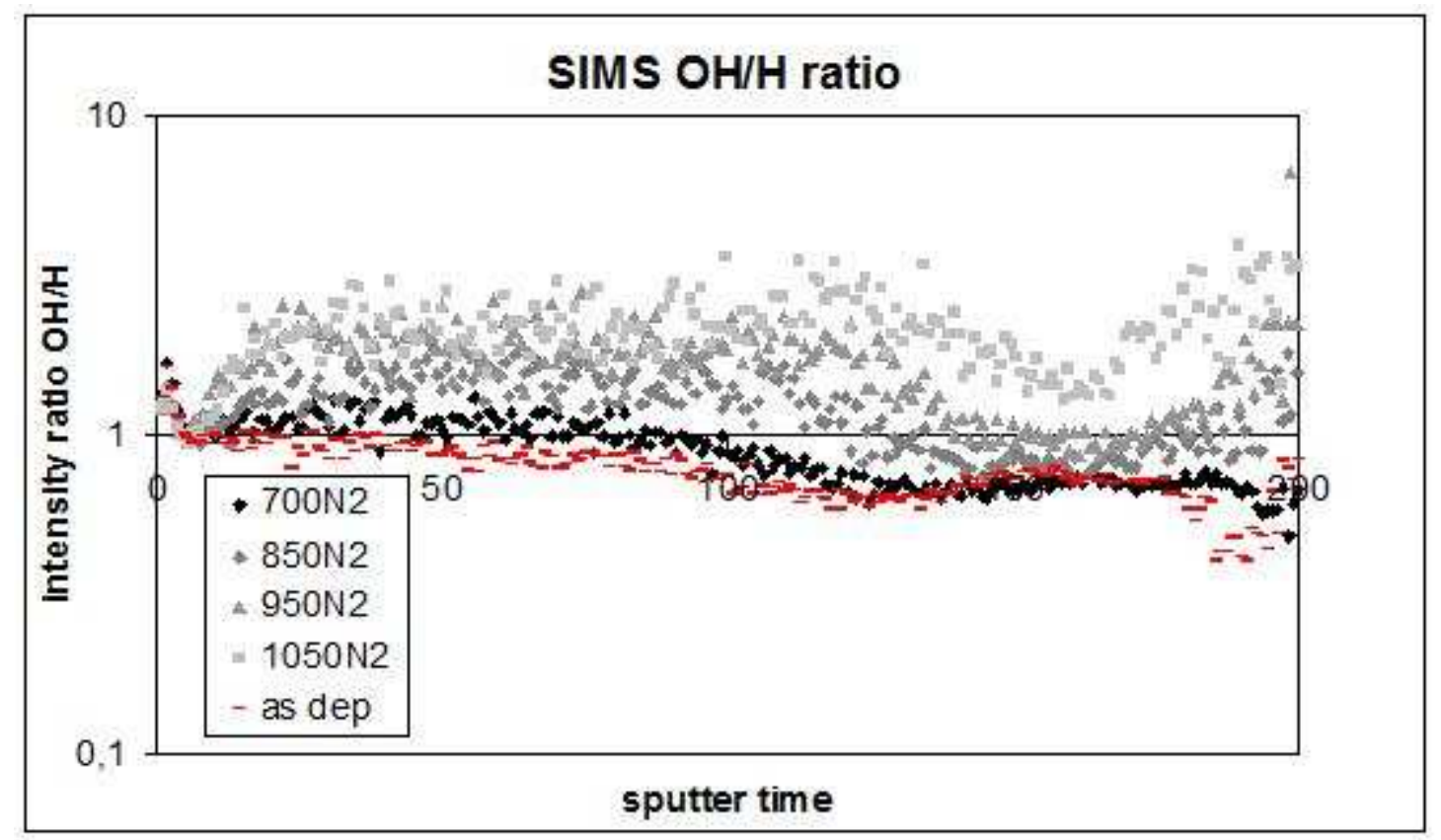

Fig. 8. OH:H ratio from Tof-SIMS for $\mathrm{Al}_{2} \mathrm{O}_{3}$ annealed at different temperatures

\section{Electrical Characterization}

Parasitic trapping in Alumina was characterized by Capacitance-voltage measurements with a mercury probe on n-type wafers as shown in the inset of Figure 9.

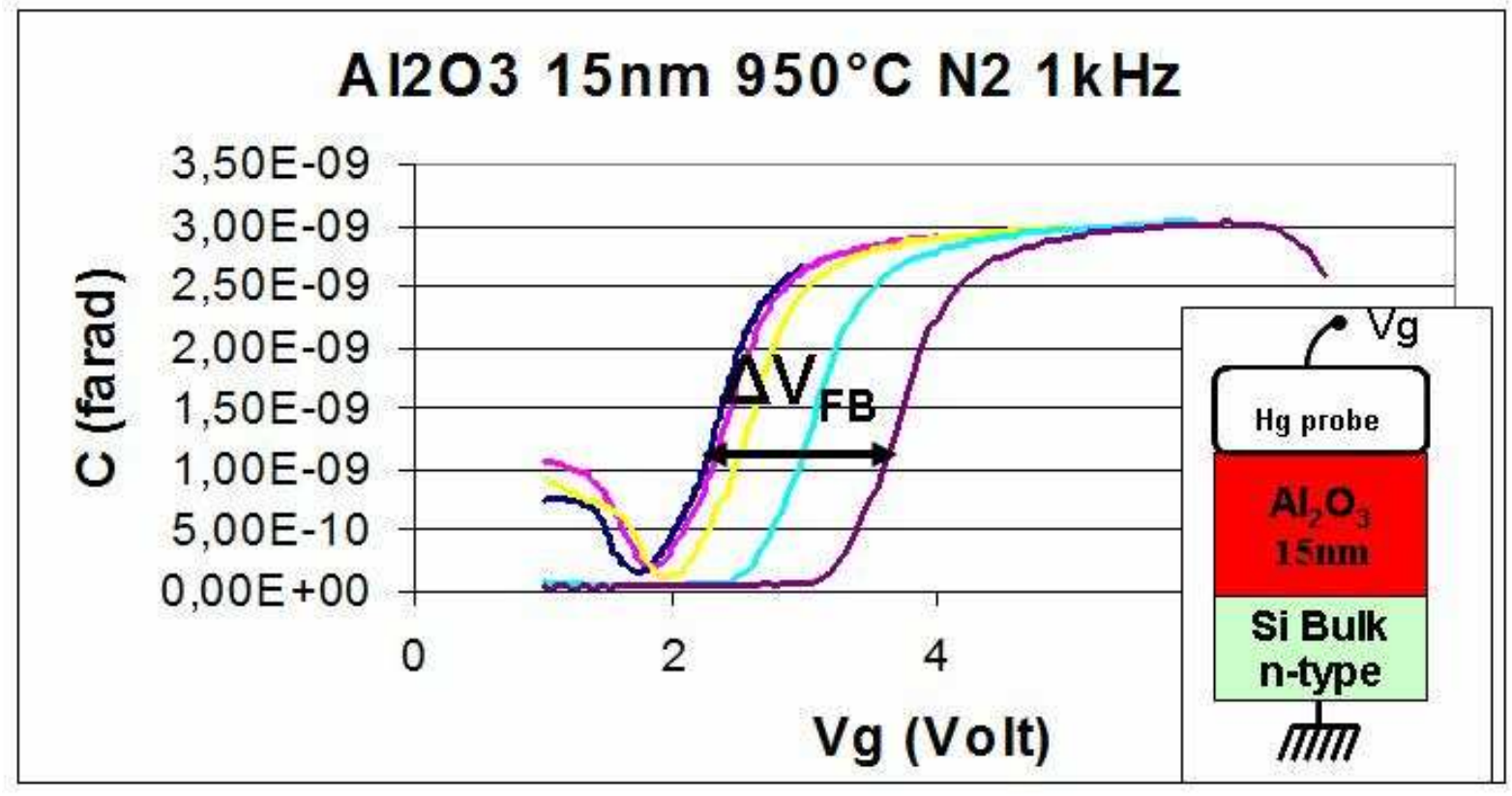

Fig 9. C(V) measurements of alumina annealed at $950^{\circ} \mathrm{c}$ under $\mathrm{N}_{2}$ 
$\mathrm{C}(\mathrm{V})$ measurements were performed at $1 \mathrm{kHz}$ from accumulation to inversion at different $\mathrm{Vg}=3-8$ volts so that the alumina layer gets charged in accumulation at the beginning of the measurement. The flat band voltage is shifting to positive values when $\mathrm{Vg}$ is increasing, indicating that negative charges are trapped in the alumina layer. The parasitic trapping in alumina is therefore characterized by this flat band voltage shift $\Delta \mathrm{V}_{\mathrm{FB}}$ as indicated in Figure 9. In order to compare the parasitic trapping of alumina samples after different anneals, we did normalize the applied voltage $\mathrm{V}_{\mathrm{G}}$ minus initial flat band voltage $\mathrm{V}_{\mathrm{FB} 0}$ by the equivalent oxide thickness (EOT). Figure 10 presents the flat band voltage shift $\Delta \mathrm{V}_{\mathrm{FB}}$ for alumina with different nitrogen anneals as a function of the electric field applied on the sample $\left(\left(\mathrm{V}_{\mathrm{G}}-\mathrm{V}_{\mathrm{FB} 0}\right)\right.$ normalized by EOT).

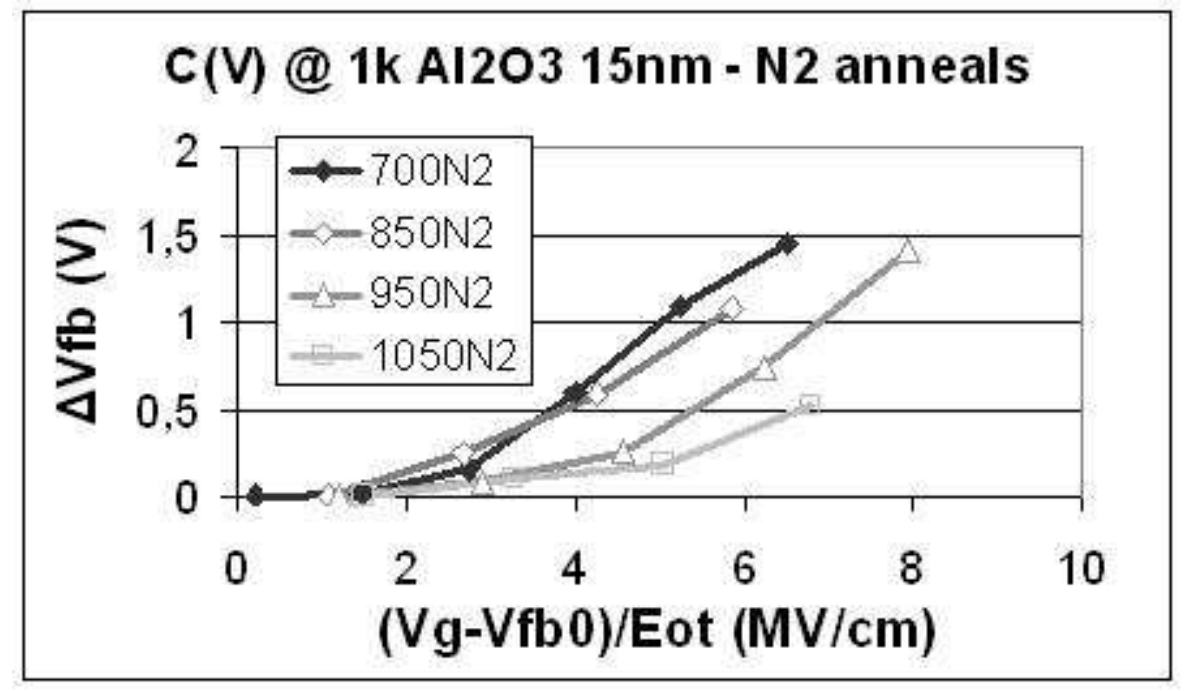

Fig 10. Normalized trapping for $\mathrm{N}_{2}$ annealed alumina

Under nitrogen anneals, trapping in alumina clearly decreases when the annealing temperature is increased. The next figure (Fig 11.) shows the comparison of trapping between nitrogen and oxygen annealed samples. Oxygen and nitrogen annealed alumina are compared at two temperatures: $700^{\circ} \mathrm{C}$ that corresponds to amorphous alumina and $1050^{\circ} \mathrm{C}$ that corresponds to crystalline alumina. The two oxygen annealed alumina show the same low trapping at any temperature, similar to alumina annealed at $1050^{\circ} \mathrm{C}$ under nitrogen. 


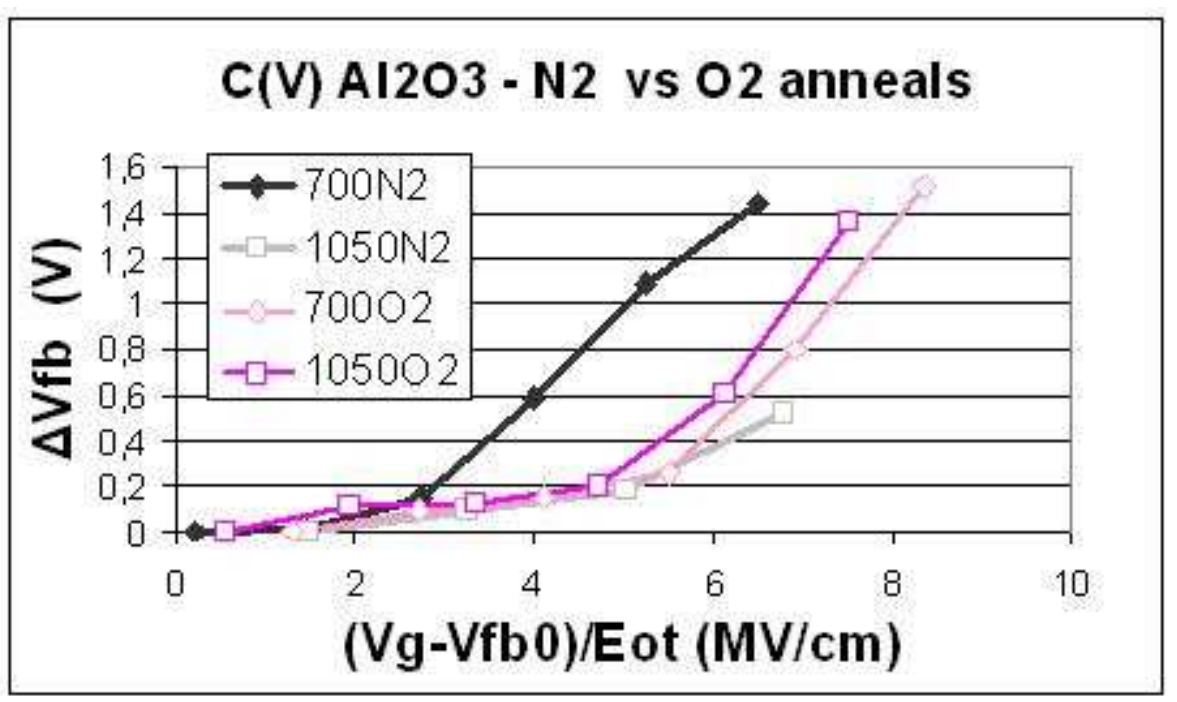

Fig 10. Normalized trapping: comparison between $\mathrm{O}_{2}$ and $\mathrm{N}_{2}$ annealed alumina

Trapping appears independant of the crystalline structure or the annealing temperature of the alumina sample. The only parameter that correlates well with trapping is the total hydrogen concentration (see Fig 11).

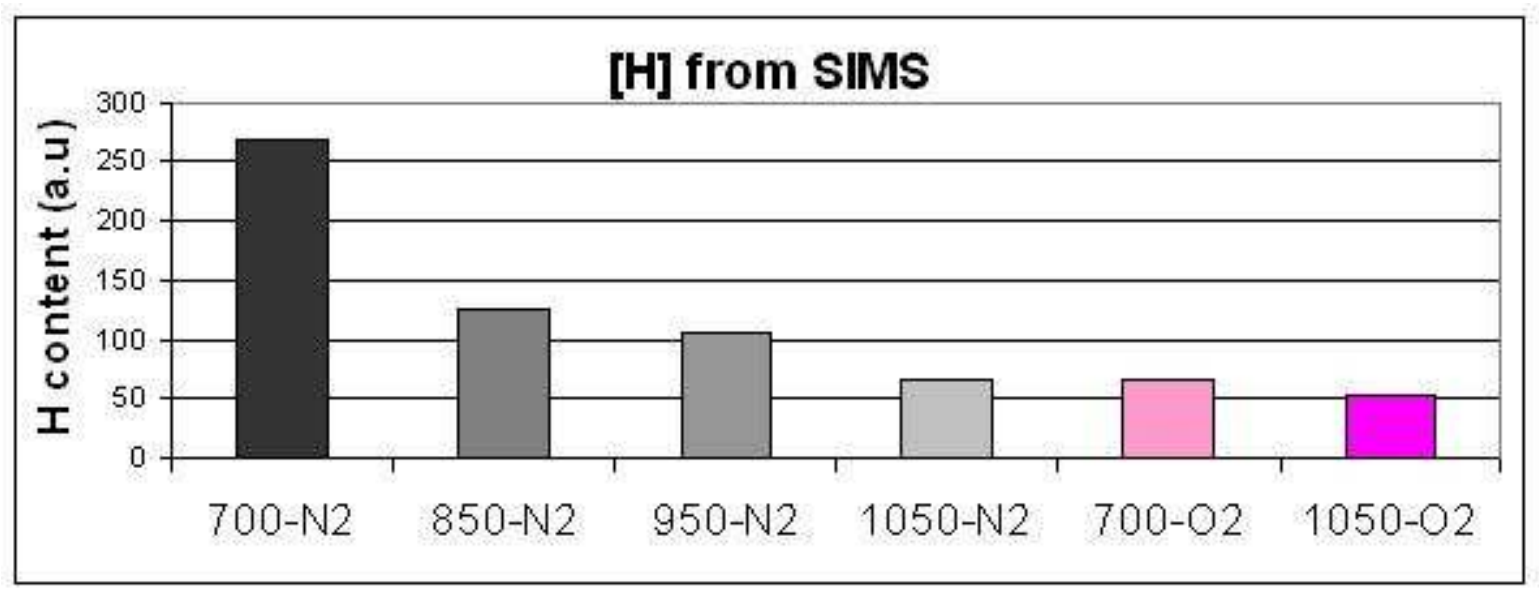

Fig 11. Hydrogen content from Tof-SIMS

We therefore have a good correlation between the total hydrogen content from Tof-SIMS measurements and trapping in alumina.

\section{Conclusion}

Alumina layers of $15 \mathrm{~nm}$ deposited using ALD from water and TMA followed by RTA have been characterized. After a low temperature anneal (up to $700^{\circ} \mathrm{C}$ ) alumina remains 
amorphous with low stress and density values. At higher temperatures (above $850^{\circ} \mathrm{C}$ ) alumina is crystalline ( $\gamma$-phase) with higher stress, density and optical band gap. The anneal ambience has a strong influence on hydrogen concentration: under nitrogen, a high temperature is required to reduce hydrogen content while under oxygen, hydrogen content is reduced-even at low temperature $\left(700^{\circ} \mathrm{C}\right)$. A strong correlation between hydrogen concentration and parasitic trapping in alumina has been established. Infrared MIR characterization suggests that hydroxyl groups are not responsible for trapping.

\section{References}

[1] G Molas et al. IEDM 2007.

[2] B Lefez et al. Thin Solid Films, vol 516, issues 2-4, 2007, p349-354

[3] D Bouchet et al. Ultramicroscopy 96, 2003, p139-152

[4] C Licitra et al. AIP Conf. Proc. 931, 292, 2007

[5] M Olivier et al. Materials Science in Semiconductor Processing, Vol 4, Issues 1-3, 2001, p15-18

[6] A.A. Tsyganenko et al. Materials Chemistry and Physics, Vol 26, Issue 1, 1990, p35-46 


\section{Figures and Tables caption}

TABLE I: Thickness, Density and Stress

p02

Fig. 1. FTIR-ATR Spectra of alumina with different annealing conditions p03

Fig. 2. HRTEM of $\mathrm{SiO}_{2} / \mathrm{Si}_{3} \mathrm{~N}_{4} / \mathrm{Al}_{2} \mathrm{O}_{3}$ annealed at 700 and $1050^{\circ} \mathrm{C} \quad$ p04

Fig. 3. EELS of $\mathrm{Al}_{2} \mathrm{O}_{3}$ annealed at 700 and $1050^{\circ} \mathrm{C} \quad$ p05

Fig. 4. Optical constant $\mathrm{n}$ and $\mathrm{k}$ of $\mathrm{Al}_{2} \mathrm{O}_{3}$ annealed at 700 and $1050^{\circ} \mathrm{C}$ p06

Fig 5. Tof-SIMS Hydrogen profile of $\mathrm{Al}_{2} \mathrm{O}_{3}$ after different anneal p07

Fig 6. Infrared MIR spectra for amorphous and crystalline alumina p08

Fig. 7. Normalized MIR spectra of $\mathrm{Al}_{2} \mathrm{O}_{3}$ annealed at 700 and $1050^{\circ} \mathrm{C}$ p09

Fig. 8. OH:H ratio from Tof-SIMS for $\mathrm{Al}_{2} \mathrm{O}_{3}$ annealed at different temperatures $\quad$ p10

Fig 9. $\mathrm{C}(\mathrm{V})$ measurements of alumina annealed at $950^{\circ} \mathrm{C}$ under $\mathrm{N}_{2} \quad \mathrm{p} 10$

Fig 10. Normalized trapping for $\mathrm{N}_{2}$ annealed alumina $\quad$ p11

Fig 10. Normalized trapping: comparison between $\mathrm{O}_{2}$ and $\mathrm{N}_{2}$ annealed alumina $\quad \mathrm{p} 12$

Fig 11. Hydrogen content from Tof-SIMS p12 